that it brings in extra money. It follows that the worker must be guaranteed that his wage will be maintained even if the amount of physical effort required is less than was necessary before the improvements were effected. The acceptance by all concerned of any new work tasks is vital and can only be achieved by explaining in detail to everybody exactly how the measurements have been arrived at; no trouble is too much to take to ensure full understanding.

\section{British Instruments for Radioactive Measurement}

TyE Scientific Instrument Manufacturers Association, in conjunction with the Atomic Energy Research Establishment of the Ministry of Supply, have prepared an illustrated brochure describing the principal instruments required for investigations using radioactive substances that are manufactured in Great Britain. The rapid developments in this field during the past five years are emphasized by the large number of instruments recorded in the thirty-odd pages of the catalogue. The catalogue is prefaced by a short description of radioactive measurement techniques and followed by advertisements of consultants in this field. The index tabulates nearly forty kinds of instruments, principally electronic, many of which are now manufactured by more than one supplier. The brochure shows that Great Britain can offer a range and variety of such instruments which will compare favourably, both in cost and performance, with any competitor. This catalogue is of particular importance to overseas consumers contemplating purchase in Great Britain of equipment for radioactive measurements. For this reason, it is unfortunate that full technical specifications and performance data for each instrument are not provided. Many instrument manufacturers still fail to achieve a clear and factual, and concise but comprehensive, specification of their products. The rapid development in instrumentation in this field encourages one to hope that further editions will be issued. The brochure is available free of charge from the Scientific Instrument Manufacturers Association, 17 Princes Gate, London, S.W.7.

\section{Exploration of a Coast-line of the Antarctic}

ONE of the last remaining gaps in the known Antarctic coast-line was the south-western coast of the Weddell Sea. Various attempts have been made to reach this by sea, but it is now realized that the currents of that Sea pack the ice against the coast and prevent any access, at least without extreme peril to the ship. This stretch from about lat. $68^{\circ} \mathrm{S}$. to lat $70^{\circ} \mathrm{S}$., the work of the joint sledge journey of the Falkland Islands Dependencies Expedition and the United States Antarctic Research Expedition, is shown in a map, accompanying an article by $\mathrm{Mr}$. D. P. Mason, in the Geographical Journal of AprilJune this year. Large glaciers seem to pour into deep indentations, and the Larsen Ice Shelf continues in a narrow form well to the south. From the base at Stonington Island in Marguerite Bay the route was first across the peninsula of Graham Land and then southward over the shelf ice. The leader had with him A. R. C. Butson, of the Falkland Dependencies Survey, and two members of the American expedition. This part of Antarctica had previously only been roughly surveyed, and to some extent incor. rectly, from the air. Air transport was of service to the expedition in carrying supplies, but the most important exploration was in surface work.

\section{Zoological Publications from Victoria University College, New Zealand}

The Department of Zoology of Victoria College, Wellington, New Zealand, has recently commenced a series of zoological publications in the form of individual pamphlets. The first six of these, No. 1, November 1, 1949-No. 6, May 31, 1950, are now to hand. They deal respectively with a new leech, new species of Ciliata, the Ctenophores, the Kirk collection of sponges, blood parasites of birds and new bugs (Hemiptera, Homoptera), and they vary in length from seven to twenty pages. The printing throughout is of a high order, and the illustrations, whether textfigures or plates, are quite adequate. The contents mainly deal with new species or the amplification of information concerning previously described forms, the exception being that dealing with sponges. This deals with the collection of sponge material, either whole specimens or slides, made by the late Prof. Kirk. While most of them are New Zealand species, some material is from outside sources, and of this some derives from the Challenger collection worked out by Prof. A. Dendy. It has made possible the estab. lishment of a number of type specimens, holotype, syntype and merotype, as well as providing additionel data on the localities of collection. One detail that calls for note is whether these publications will be regarded as establishing priority in nomenclature under the international rules, since they carry no indication of price or availability. In view of their excellence and usefulness, it would be a pity if they were considered to be invalid.

\section{Experiments at the Grassland Research Station}

A BUlletin on "Experiments in Progress 1950" has been issued by the Grassland Research Station from Drayton, Stratford-on-Avon, Warwickshire. The Station took over the work and functions of the former Grassland Improvement Station, as from October 1, 1949 (see Nature, 163, 477; 1949). New headquarters are being established at Hurley, Berkshire, but most of the experimental work listed in the bulletin has been carried out at Drayton. The experiments in progress include some welcome new features such as the investigation of the much. neglected fungus diseases of grassland. Some useful results obtained in earlier years are included in the publication. Yields of various grass strains for hay, grazing, silage and winter keep are compared and related with live-weight increases under stock. The relative yields of dry matter per acre under different methods of management are also tabulated. Many of the results are records which will become in. creasingly valuable as the years pass, but the bulletin indicates a large amount of useful long-term work soundly established.

\section{Marine Radar for Harbour Use}

A NOTE on harbour radar services, based on an article in the Journal of the Franklin Institute, was published in Nature of September 30, p. 544. Dr. J. B. Warren, of the Department of Physics, University of British Columbia, Vancouver, has provided some additional information. He states that an Admiralty Pattern 268 was installed at Halifax, Nova Scotia, in 1946, and in May 1949 the National Research Council of Canada installed an equipment on the centre of the Lions' Gate Bridge across the First Narrows in Vancouver Harbour. A description of this installation by $\mathrm{W}$. J. Mooney appeared in Harbour and Shipping (Vancouver) of January 1950. 